\title{
METODOLOGIA DA PROBLEMATIZAÇÃO: UMA ALTERNATIVA METODOLÓGICA APROPRIADA PARA O ENSINO SUPERIOR
}

\author{
NEUSI APARECIDA NAVAS BERBEL ${ }^{1}$
}

\begin{abstract}
BERBEL, N.A.N. Metodologia da Problematização: uma alternativa metodológica apropriada para o Ensino Superior. Semina: Ci. Soc./Hum., Londrina, v.16. n. 2., Ed. Especial, p.9-19, out. 1995.

RESUMO: Diante da reiterada constatação da predominância da Pedagogia da Transmissão no Ensino Superior, o que caracteriza um ensino centrado no professor e seu saber ao invés da aprendizagem do aluno, neste artigo apresenta-se a Metodologia da Problematização, como uma alternativa metodológica com grande potencial pedagógico para preparar o futuro profissional e cidadão, requerido para uma sociedade em rápidas transformações. O texto foi construído seguindo-se os passos da própria Metodologia: observação da realidade e definição de um problema de estudo, pontos-chave, teorização, hipóteses de solução e aplicação à realidade. As características dessa Metodologia são explicadas, discutidas, analisadas, com apoio em Juan Díaz Bordenave e outros autores e algumas experiências são destacadas como suporte do processo de ação-reflexão, para as hipóteses de solução e aplicaçöes possiveis à realidade do contexto próximo do Ensino Superior, a partir do qual foi formulado o problema.
\end{abstract}

PALAVRAS-ChAVE: Metodologia da Problematização; Métodos de Ensino; Ensino Superior.

Com o objetivo de desenvolver um conjunto de idéias e propostas relacionadas à Metodologia da Problematização, este texto foi elaborado seguindo-se as etapas dessa própria Metodologia - que é destinada ao ensino ou estudo - configurando-se assim numa de suas aplicações. Cumpre esclarecer que quando chegarmos na terceira etapa, a da Teorização (item 3), abriremos um sub-item para explicar mais especificamente cada uma das etapas, e seguiremos utilizando-as até completar o texto, com a Aplicação à Realidade, como segue exposto.

\section{1 - OBSERVAÇÃO DA REALIDADE}

Dos estudantes universitários espera-se que sejam "interessados, estudiosos, dedicados, assíduos e demonstrem ter iniciativa. (...) que participem ativamente das aulas teóricas e práticas e procurem complementação em bibliografia recomendada. (...) que sejam responsáveis, muito inteligentes, educados, e além dessas qualidades, assimilem bem o que é ensinado" (MACHADO, 1994, p.70).

Isso foi revelado por uma pesquisa realizada com professores do Curso de Medicina Veterinária da UEL. Na realidade, como a autora concluiu, esta é uma expectativa bastante idealizada pelos professores, pois "as características atribuidas por eles ao bom aluno nem sempre são desenvolvidas pela Universidade" (p.72). A autora ainda afirma que "tem sido verificado através de pesquisas que o trabalho escolar se pauta principalmente na transmissão/aquisição de conhecimentos ou técnicas, ou seja, o trabalho com o domínio cognitivo do aluno.
Assim, parece ser um tanto contraditório os professores gerarem a expectativa de terem alunos com aquelas características, sendo que a Universidade pouco faz para desenvolvê-las. Então, o aluno teria que vir pronto para a Universidade, repleto de virtudes e de atitudes positivas, para ser considerado bom aluno" (MACHADO, 1994, p.72).

Em pesquisa realizada em 1990 junto a professores que ensinam a Metodologia do Ensino Superior no país (BERBEL, 1992), constatamos que as três formas de ensino mais utilizadas são a exposição, a discussão e a leitura. Sendo essa Disciplina a única "pedagógica" inserida na Pós-Graduação "Lato-Sensu", com o intuito de preparar professores para atuar no Magistério Superior, depreende-se que não será através dela (com raras exceções) que os futuros professores - profissionais de todas as áreas - estarão sendo preparados para ultrapassar as formas mais tradicionais de ensino, que incluem a exposição oral como a mais utilizada, como também afirmou MACHADO (1994).

- Por que seria necessário ultrapassar essa forma de ensino?

Antes de responder a pergunta, é importante afirmar que não desejamos anular ou ignorar a importância que tem a exposição em diversas situações de ensino. O que é preciso ultrapassar é o seu uso exagerado, o seu uso exclusivo, sem alternativas. Para grande número de professores do ensino superior essa é a única possibilidade, tendo sido o modelo aprendido e então reproduzido. Se assim foi feito com eles e eles chegaram até onde chegaram - a ser professores de 30 Grau!! - por que mudar? Além disso, afirmam alguns, 'é a forma mais

1 - Doutora em Educaçăo. Professora do Departamento de Educaçăo da Universidade Estadual de Londrina, Londrina, PR., Brasil, Caixa Postal 6001, CEP 86051-970. Responsável pela Disciplina Didática e Fundamentos do Ensino, cujo desenvolvimento pela primeira vez em 1994, possibilitou aos alunos a realizaçăo dos trabalhos que seguem apresentados nesta revista.

Semina: Ci. Soc./Hum. v. 16., n. 2, Ed. Especial, p. 9-19. out. 1995 
prática, rápida e eficiente para se passar todo o programa!'. Mas... com que conseqüências?

A exposição oral, como outras tantas formas de transmitir informações, colocam o professor como centro do processo de ensino-aprendizagem. Enquanto o professor que sabe, transmite o que sabe, o aluno que não sabe ouve e às vezes anota o que ouve, reproduzindo as informações quando sọlicitadọ, em provas de verificação da aprendizagem.

Em depoimentos dos melhores alunos do Curso de Medicina da UEL, - considerados na pesquisa de Moreira como aqueles que obtiveram as melhores médias acumuladas durante o curso, estes revelaram não possuir um método de estudo específico, estudando como podem ou sabem e como puderam, desde o $2^{\circ} \mathrm{Grau}$, como conta MOREIRA (1994):

\begin{abstract}
"O aluno $M$ disse que sempre estudava só na véspera. Tinha o acompanhamento dos pais sim e raramente estudou em grupo. Como mé todo de estudo, usava a memonização: 'para memorizar eu tinha que andar e falar alto. Agora não faço mais isso (...). É ficar sentado, kndoe relendo, nem escrever eu escrevo' (p.97)

"Oaluno L (...) buscava sempre mais dois ou três livros além do indicado na escola. Estudava bastante e por sua própria conta (...) O trabalho de grupo lhe atrapalhava. Se estivesse sozinho ia mais rápido. No $2^{2}$ Grau estudava muito escrevendo, resumindo, mas levava muito tempo. Depois que entrou na Universidade, nãotem mais tempo para isso e como tem dificuldade para gravar, então lê a mesma coisa várias vezes: lê 3, 4,5 vezes." (p.97)

"Quantoao estudoem grupo, dos cincoentrevistados, três manifestaram não apreciar, por baixar seu nivel de concentração e aproveitamento. Um deles aprova o estudo em grupo quando o assunto é de exatas e outro quando é para aulas práticas" (p.99).
\end{abstract}

Podemos perceber que a transmissão e retenção de informações é uma prática assimilada por professores e alunos - de $2^{2}$ Grau e também de $3^{2}$ Grau - no caso, na área médica. No entanto, o que se requer desses futuros profissionais (alunos de Medicina), ao completarem seu curso e mesmo na fase de conclusão do mesmo - em que estarão em contato com pacientes reais, com certeza diferentes dos casos da literatura - é que estejam habilitados, entre outras coisas, para ajudá-los a resolver suas questōes de saúde (ou de doença). Ou seja: que sabam diagnosticar seus problemas e encaminhar para uma solução (tratamento, cura, prevenção).

A solução dos problemas sociais, econômicos e políticos da sociedade brasileira e da região onde se realiza a Educacaão Superior, está prevista como um de seus objetivos, no Projeto de Lei de Díretrizes e Bases da Educação Nacional LDB, aprovada pela Câmara Federal em 13.05.93, mas ainda em tramitação no Senado Federal (FONSECA, 1994).

Como vão participar compromissadamente da solução aos problemas locais, regionais ou nacionais, os profissionais de nível superior que não tiveram um mínimo de preparo para isso em seu tempo de formação? Quantos anos mais precisarão até que adquiram por conta própria e/ou por força do ensaio-e-erro essa capacidade de enfrentar problemas e lhes propor alternativas viáveis de solução? Qual o compromisso da Universidade com a sociedade em que se insere, principalmente em momentos de acelerada transformação das condiçōes gerais de vida da Humanidade, no limiar do século $X X I$ ?

Essas questões requerem essencialmente uma resposta política e cultural da Universidade, mas requerem também uma resposta pedagógica. Uma resposta político-pedagógica, de revisão cultural do papel do professor universitário ao contribuir para o cumprimento das funções da Universidade e uma resposta de reflexão crítica e intervenção sobre essa REALIDADE OBSERVADA e vivida em nossa Universidade e em nossa Sociedade.

\section{1 - Problema}

São muitos os estudos e os dados que poderiam ser aqui arrolados sobre a Realidade do Ensino Superior. São muitas as possibilidades de estudo e discussão que o tema até agora introduzido suscita, mas para atingir o objetivo deste texto, destaca-se o seguinte PROBLEMA:
"Qual alternativa metodológica se apresen- ta com potencial pedagógico no sentido de preparar o aluno do Ensino Superior para atuar como profissional e cidadão em seu meio?"

\section{2 - PONTOS-CHAVE}

Considerando-se que a metodologia de ensino (métodos, técnicas, procedimentos etc. e recursos auxiliares) constitui o meio, a forma, o caminho a ser percorrido e orientado pelo professor para o desenvolvimento de seus alunos dentro de determinada perspectiva, e que este caminho é sempre historicamente determinado, podemos destacar para esta reflexão os seguintes PONTOS-CHAVE:

2.1 - Para o professor fazer uso de uma metodologia de ensino, o primeiro passo é conhecer suas características - sua justificativa, suas etapas, suas implicações etc.. A melhor forma de conhecer é vivenciar o processo, para poder refletir sobre sua utilidade, a relação teoriaprática nela presente e encontrar as suas próprias razões para decidir pela importância e possibilidade ou não de utilização com seus alunos.

2.2 - É importante reconhecer que as formas de ensinar têm conseqüências que vão além da aprendizagem de um conjunto de informações, sejam teóricas ou práticas. Elas estabelecem um estilo de interação do professor com seus alunos, dos alunos e professores com os conhecimentos e com o mundo, possibilitando experiências que podem servir para influenciar outras situações de vida dos próprios sujeitos.

2.3 - Toda metodologia de ensino, para ser utilizada, deve ser organizada, levando-se em conta as condiçōes reais de tempo, local, nível de aprendizagem dos alunos e principalmente as possibilidades de sua participação efetiva, de modo a se obter o resultado desejado. Para isso, e dessa maneira, resguardada sua orientação básica, o uso deve ser flexível para permitir a sua apropriação pelas pessoas e o alcance dos objetivos pretendidos.

2.4 - A mudança na forma do professor trabalhar com

Semina: Ci. Soc./Hum. v.16., n. 2, Ed. Especial, p. 9-19. out. 1995 
seus alunos implica esforço adicional ao já empreendido para agir como de costume, principalmente se ainda segue as formas tradicionais de transmissão e recepção de informações. Esse esforço adicional solicita do professor uma ampliação da compreensão dos fundamentos teórico-metodológicos do ensino, que contam com explicaçōes filosóficas, políticas, psicológicas, históricas etc.

2.5 - O Ensino Superior no Brasil tem objetivos relacionados ao preparo do homem (jovens adultos e adultos mais maduros) para a vida em sociedade. Voltase para a preparação profissional, para a construção e reconstrução do saber, para o preparo do cidadăo e sua participação na construção de umą sociedade justa, livre e desenvolvida. Nesse caminho, os problemas são cada vez maiores e precisam ser enfrentados e resolvidos racional e criativamente, individual e coletivamente. Há que se buscar formas de trabalhar com os alunos de modo apropriado, respeitando-Ihes suas caracteristicas essenciais e proporcionando-lhes o desenvolvimento de atitudes, habilidades, e aquisição de conhecimentos compativeis com os objetivos do Ensino Superior.

2.6 - A desvalorização político-econômica da educação em nossa sociedade é um desafio constante e bastante forte para todo professor compromissado com sua profissão, no sentido de empreender um trabalho de superação de toda a falta de condições a que é submetido. Ele é provocado a contrariar a maré e lançar-se persistente e criativamente na luta política e pedagógica para conquistar o reconhecimento social do sentido construtivo da educação na vida do homem e de toda a sociedade; assim como a sua própria valorização profissional.

\section{3 - TEORIZAÇÃO}

A alternativa metodológica aqui apresentada como uma possivel resposta ao problema identificado é a Metodologia da Problematização, proposta por Charlez Maguerez, aplicada e explicada, por primeira vez em Iivro no Brasil, por BORDENAVE \& PEREIRA, em 1977, na 1". edição de "Estratégias de Ensino - Aprendizagem".

Essa metodologia, denominada por Maguerez (BORDENAVE \& PEREIRA, 1982) por "Método do Arco", possui uma lógica bastante próxima do método científico, mas não se confunde com ele. Também se assemeIha em muitos pontos com o método de resolução de problemas (PBL), mas dele se distingue em vários pontos importantes.

Nesta fase do texto será apresentada a Metodologia da Problematização através da contribuição de alguns autores para a sua compreensão, à qual será acrescentada a nossa compreensão até o momento. Na seqūêncla, apresentaremos alguns registros de oportunidades que tivemos de sua aplicação, culminando com os trabaIhos que são apresentados nos próximos artigos desta revista.

\section{1 - Caracteristicas Gerais da Metodologia da Problematização}

BORDENAVE \& PEREIRA (1982), ao anunciar a proposta de tratamento que dariam a todos os capítulos de seu livro, seguindo o esquema de Maguerez, começam por distinguir dois tipos de educação - a educação bancária ou convergente e a educação problematizadora ou libertadora. Segundo eles a educação bancária, baseada na transmissão do conhecimento e da experiêncla do professor, atribui importância suprema ao conteúdo da matéria, sem preocupar-se com o aluno como pessoa integral e como membro de uma comunidade. Conseqüentemente, "o aluno é passivo, grande tomador de notas, exímio memorizador" (p.10). Desse modo, ele val ter facilidade para tratar com conceitos abstratos mas não vai ter facilidade para resolver problemas concretos de sua realidade.

Já a educação problematizadora possui outra proposta. Partindo do pressuposto de que "uma pessoa só conhece bem algo quando o transforma, transformando. se ela também no processo", BORDENAVE \& PEREIRA (1982, p.10) apresentam a solução de problemas como uma forma de participação ativa e de diálogo constante entre alunos e professores para se atingir o conhecimento. Não um problema qualquer, ou imaginado pelo professor para estimular o potencial intelectual do aluno, mas problemas reais, percebidos pela obsenvação direta da realidade em foco.

O esquema representativo da proposta de Maguerez e utilizado por BORDENAVE \& PEREIRA (1982) é o seguinte:

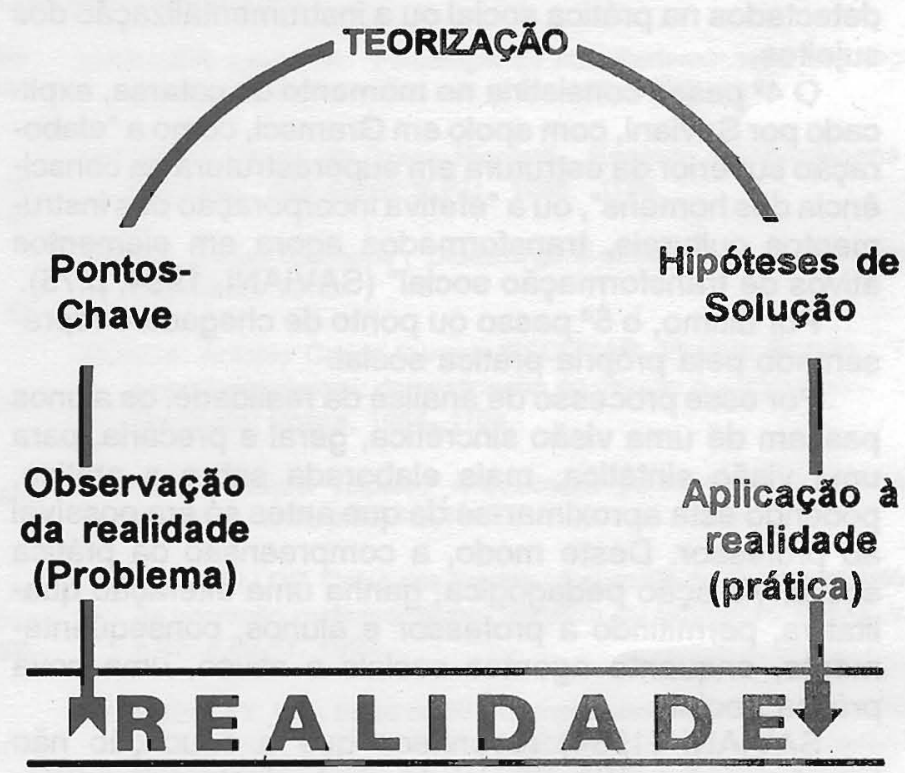

As etapas deste esquema serão desenvolvidas no item 3.3

Em outro texto, BORDENAVE $(1989$, p.24) explica que

"Em um mundo de mudanças rápidas, o importante não são os conhecimentos ou idélas nem os comportamentos corretos e fáceis que se espera, mas sim o aumento da capacidade do aluno - participante e agente da transformação social - para detectar os problemas reais e buscar para eles soluções originais e criativas. Por essa razão, a capacidade que se deseja desenvolver é a de fazer perguntas relevantes em qualquer situação para entendê-los e seir capaz de resolvê-los adequadamente". 
BORDENAVE encontra em SAVIANI o reforço para suas idélas sobre os métodos para uma educação voltada para a democracia. SAVIANI (1984), ao distinguir os métodos novos e tradicionais em seus aspectos pedagógicos, de forma associada aos aspectos histórico-sociais e ideológicos presentes em suas formulações e aplicações, precọniza um tipo de metodologia que mantenha continuamente a vinculação entre educação e sociedade.

Seguindo um esquema de passos, como o fizeram HERBART (1776-1841) e DEWEY (1859-1952) em momentos anteriores da história da educação, SAVIANI (1984) propõe como $1^{2}$ passo ou ponto de partida, a prática social, que é comum a professor e alunos. Embora sejam diferentes os níveis de compreensão e experiéncias destes, ambos lucrarão pela articulação da experiência pedagógica com a prática social de que participam.

Como $2^{2}$ passo, Saviani propõe a problematização, que explica como sendo o momento de "detectar que questōes precisam ser resolvidas no âmbito da prática social e, em consequééncia, que conhecimento é necessário dominar" (SAVIANI, 1984, p.74). Na seqüência, o $3^{9}$ passo seria a apropriação dos instrumentos teóricos e práticos necessários ao equacionamento dos problemas detectados na prática social ou a instrumentalização dos sujeitos.

O $4^{2}$ passo consistiria no momento de catarse, explicado por Saviani, com apoio em Gramsci, como a "elaboração superior da estrutura em superestrutura na consciência dos homens", ou a "efetiva incorporação dos instrumentos culturais, transformados agora em elementos ativos de transformação social" (SAVIANI, 1984, p.75).

Por último, $05^{2}$ passo ou ponto de chegada é representado pela própria prática social.

Por esse processo de análise da realidade, os alunos passam de uma visão sincrética, geral e precária, para uma visão sintética, mais elaborada sobre a prática, podendo esta aproximar-se da que antes só era possivel ao professor. Deste modo, a compreensão da prática social, via ação pedagógica, ganha uma alteração qualitativa, permitindo a professor e alunos, conseqüentemente, enquanto agentes sociais e ativos, uma nova prática social.

SAVIANI (1984) reconhece que a educação não transforma a prática social de modo direto e imediato, mas de modo indireto e mediato, na medida em que age sobre os sujeitos da prática. Se apoia para essa conclusão em VÁZQUEZ, que afirma:

\footnotetext{
"A teoria em si (...) não transforma o mundo. Pode contribuir para sua transformação, mas para isso tem que sair de si mesmo, e, em primeiro lugar, tem que ser assimilada pelos que vão ocasionar, com seus atos reais, efetivos, tal transformação. Entre a teoria e a atividade prática transformadora se insere um trabalho de educação das consciências, de organização dos meios materiais e planos concretos de ação; tudo isso como passagem indispensável para desenvolver açóes reais, efetivas. Nesse sentido, uma teoria é prática na medida em que materia-
}

liza, através de uma série de mediações o que antes só existia idealmente, como conhecimento da realidade ou antecipação ideal de sua transformação" (VÁZQUEZ, 1977, p.206-207).

Tanto BORDENAVE quanto SAVIANI entendem a educação como uma atividade mediadora entre o individuo e a sociedade, por isso o primeiro enfatiza e o segundo formula metodologias muito semelhantes, partindo da realidade e retornando para ela, passando pelo processo de síncrese, análise e síntese do conhecimento. A inspiração de SAVIANI (1984) vem da concepção dialética de ciência, tal como formulou Marx no "método da economia política" e o autor afirma que esse movimento constitui uma orientação segura tanto para o método científico quanto para o método de ensino.

O interesse nosso ao trabalhar com a metodologia da problematização incide sobre o ensino. No entanto, utilizada como forma de estudar, de aprender, tal metodologia se desenvolve através da investigação. Não a investigação científica clássica, que tem sido praticada por pesquisadores propriamente ditos, mas uma investigação necessária para aprender, que vai além da identificação daquilo que já está disponivel na literatura. $\mathrm{O}$ confronto entre as percepções primeiras dos aprendizes com o conhecimento já elaborado, permite uma análise e compreensão mais profunda, lógica e porque não dizer científica do que acontece na realidade, para se chegar à transformação dos sujeitos e conseqüentemente da própria realidade.

Recentemente, a problematização tem sido apontada como uma estratégia pedagógica na área da saúde, tendo em vista uma Gestão de Qualidade para o desenvolvimento amplo dessa área.

NOGUEIRA (1994) busca em Edwards Deming e em Hilton Japiassu entre outros, sustentação para a exploração da problematização em termos mais modernos, mas faz um caminho de volta até o filósofo Sócrates para explicar a importância da atitude problematizadora diante de certas verdades bem estabelecidas $e$ isso através do que chama de perguntas pertinentes.

Segundo NOGUEIRA (1994, p.138), "Sócrates insistia em perguntar não acerca de objetos abstratos e gerais, mas sobre os detalhes da vida cotidiana, buscando as evidências empíricas e racionais". Em outra passagem, Nogueira afirma que "a dialética de Sócrates foi pioneira em sua preocupação com o sentido social e técnico das artes e ofícios que se reunem usualmente numa cidade".

A dúvida, a pergunta, a incerteza, a problematização, são apontados como princípios da aprendizagem continua da Qualidade por esse autor, ao afirmar que:

"(...) a pergunta é posta como um desafio a uma investigação eventual, que deve levar a identificar evidências e estabelecer a veracidade dos fatos. A problematização instaura a dúvida como princípio e como método de conhecimento" (NOGUEIRA, 1994, p.135).

A Metodologia da Problematização tem sido utilizada também para o treinamento de Recursos Humanos na 
área da saúde, na preparação de trabalhadores para o serviços já há alguns anos. Em Documento da Organiżação Pan-Americana de Saúde, SOUZA et al. (1991, p.3) assim se expressaram:

\begin{abstract}
"A alternativa metodológica parto do pres. suposto de que este processo deva ser recortado a partir da realidade das práticas concretas da saúde, considerando seus determinantes limites o buscando a interação com as exigencias do trabalho (...). O recorte da realidade pressupóe igualmente a compreensão do contexto de um projeto político de transformação dos servicos de saúde".
\end{abstract}

Aí está presente a direção a ser seguida - a transformação da realidade. Mais adiante, as autoras defendem que para esse trabalho,

\begin{abstract}
"a metodologia tem que garantir uma adequação ao sujeito que aprende, para que o mesmo possa, a partir dos seus esquemas 'menos elaborados' abstrair as relações de causalidade e desenvolver esquemas mais elaborados e científicos. Nesta situação, 0 método facilita a apreensão do objeto, tomando o referencial da problematização do mesmo e viabilizando o processo de abstracão cada vez mais referenciado à totalidade" (SOUZA et al.; 1991, p.30).
\end{abstract}

Quando aplicada ao Projeto Larga Escala, de formação dos trabalhadores nos serviços, a metodologia buscou:

\begin{abstract}
"viabilizar a interação entre o sujeito e objeto no ambiente de trabalho, considerando as formas de aprender do sujeito o recortes do objeto que permitam partir de seu referencial de percepção da realidade, sem negar seus conhecimentos de prática e senso comum, para construir novos conhecimentos mais elaborados e específicos, de acordo com a habilitação profissional. 0 sujeito tem voz a constrói ativamente o seu conhecimento; o instrutor coloca-se como um coadjuvante que organiza o caminho e facilita esta construção". (SOUZA et al., 1991, p.33-34).
\end{abstract}

Podemos perceber que, por diferentes fontes de inspiração, porém com pontos comuns de preocupação, a problematização vem sendo apontada como importante método de conhecimento. Por suas características, a problematização supõe e/ou estimula o desenvolvimento de processos mentais superiores, esperados ou atribuídos à inteligência adulta. Além disso, estimula e desenvolve nos alunos (e como vimos acima, também nos trabalhadores em formação continuada), atitudes críticas e crlativas em relação ao meio em que vivem e à profissão para a qual se preparam. Desse modo, seu potencial de cidadão é mobilizado de forma intencional e sistematizada, como compete à Instituição Escolar proceder.

\section{2 - O Método de Resolução de Problemas a Metodologia da Problematizaçāo.}

A resolução de problemas como método de ensino não é uma novidade pedagógica. Fol desenvolvida a partir das idéias de Dewey, no início deste século. Dewey propunha a solução de problemas como forma de desencadear o pensamento reflexivo, como a forma mais elevada de pensamento. O papel da escola nesse sentido seria o de criar condiçōes favoráveis para os alunos desenvolverem formas de pensar reflexivamente, de modo a atingir uma lógica no ato de pensar.

A metodologia da problematização distingue-se do método de solução de problemas exatamente na perspectiva da trans-form-ação, ou seja: na idéla de que se deseja ultrapassar a forma já existente de se tratar as questōes do conhecimento e da vida em sociedade, através de uma nova ação, subsidiada pela reflexão metódica e informada cientificamente.

Em outra oportunidade já desenvolvemos um pouco esta comparação. Dizíamos que
"as duas concepções metodológicas têm pontos comuns e pontos diferentes. O pro- cesso em si é muito semelhante. Trabalha- se com o objetivo de resolver um problema $e$, nesse sentido, é um processo multo pare- cido com a metodologia de pesquisa cienti- fica. (...) A partir de um problema, busca-se compreendê-lo, fundamentá-lo, buscam-se dados para isso, que são analisados e dis- cutidos; por último, são elaboradas hipóte- ses de solução, que devem ser colocadas em prática para serem comprovadas e vali- dadas" (BERBEL, 1994, p.63).

No entanto, os dois métodos distinguem-se $1^{9} \mathrm{em}$ sua concepção, $2^{\circ}$ em seu ponto de partida e $3^{\circ} \mathrm{em}$ seu ponto de chegada, o que em linhas gerais pode ser assim caracterizado:

$1^{2}$ - O Método de Solução de Problemas tem sua origem com o filósofo e educador John Dewey, na 1 metade do século. É um dos métodos mais característicos da Escola Ativa ou Escola Nova, ao lado do Método de Projeto, do Método da Descoberta e do Estudo do Meio.

LIBÂNEO (1985) classifica as posturas pedagógicas desse momento da educação dentro da tendéncia que denominou de "liberal renovada progressivista" ou ainda pragmatista. Para esse autor, essa tendência acentua, tal como a tradicional, "o sentido da cultura como desenvolvimento das aptidões individuais. Mas, a educação é um processo interno, não externo; ela parte das necessidades $e$ interesses individuais necessários para a adaptação ao meio" (LIBÂNEO, 1985, p.22). Para isso, "a escola deve se organizar de forma a retratar, o quanto possivel, a vida".

Metodologicamente, enfatiza-se a idéia do aprender fazendo e o Método de Solução de Problemas deve apresentar problemas que retratem o máximo possivel, a vida. 
Sem dúvida nenhuma, as propostas da Escola Ativa ou Escola Nova e dentro dela os métodos experimentais, constituem um grande avanço e uma grande contribuição em relação à pedagogia tradicional. No entanto, como ponderou NÉRICl (1973, p.93), "o método de problemas faz ênfase no raciocínio, na reflexão, lidando preponderantemente com idéias ao invés de coisas".

Além disso, as idéias de Dewey e outros de seu tempo, como manifestações da educação liberal, reforçam a posição de que os indivíduos têm as mesmas oportunidades e se desenvolvem segundo suas capacidades, pressuposto já amplamente debatido pelos seguidores da linha histórico-crítica.

A Metodologia da Problematização surge dentro de uma visão de educação libertadora, voltada para a transformação social, cuja crença é a de que os sujeitos precisam instruir-se e conscientizar-se de seu papel, de seus deveres e de seus direitos na sociedade. Trata-se de uma concepção que acredita na educação como uma prática social e não individual ou individualizante. Seus fundamentos estão em PAULO FREIRE, depois DERMEVAL SAVIANI, JOSÉ CARLOS LIBÂNEO, CIPRIANO CARLOS LUCKESI e outros, todos vivos, atuais educadores e pensadores brasileiros, inspirados nas teorias histórico-críticas.

$2^{2}$ - Os dois métodos são distintos em seu ponto de partida. Como já demonstramos antes (BERBEL, 1994), o método de problemas tem como ponto de partida um problema bem formulado pelo professor para os alunos. A metodologia da problematização tem como ponto de partida a realidade, onde as questões em estudo estão acontecendo. Observada sob diversos ângulos, a realidade manifesta-se para alunos e professor, através dos fatos concretos e daí são extraídos os problemas.

$3^{2}$ - Os dois métodos distinguem-se no seu ponto de chegada. O método de resolução de problemas pretende chegar a um resultado. Nesse percurso o aluno pesquisa, discute com seu professor e colegas ou ainda outros profissionais, formula suas hipóteses diagnósticas e de solução e assim completa o processo de estudo. A metodologia da problematização pretende retornar à realidade, com informações, sugestões e/ou ações efetivas.

Os dois métodos são válidos e importantes, mas é preciso compreender que se voltam para objetivos diferentes.

O método de resolução de problemas estimula o raciocínio, a exploração lógica dos dados, a generalização etc., ou seja, o desenvolvimento de habilidades intelectuais e a aquisição de conhecimentos, preponderamente. A metodologia da problematização, além dessas aquisições, mobiliza o potencial social, político e ético dos profissionais em formação. Proporciona a estes amplas condições de relação teoria-prática. Estimula o trabalho junto a outras pessoas da comunidade, no local onde os fatos ocorrem; provocam algum tipo de alteração em todos os sujeitos, mesmo durante o processo, além das possibilidades de aplicação das hipóteses de solução. Alunos e professores juntos, saem dos muros da Universidade e aprendem com a realidade concreta. Aumentam as chances de, se estimular nos alunos uma postura de cidadãos mais conscientes, críti- cos e comprometidos com o seu meio. Eis aí algumas razōes porque escolhemos trabalhar com a Metodologia da Problematização (BERBEL, 1994).

\section{3 - As etapas da Metodologia da Problematização: alguns esclarecimentos, tendo em vista a sua utilização.}

O esquema já apresentado no item 3.1 pode ser melhor entendido, quando recorremos à explicação de BORDENAVE (1989) e a ela associamos a compreensão que fomos elaborando com a experiência de utilização da metodologia.

3.3.1 - Como já foi amplamente pontuado, o estudo se dá a partir de um determinado aspecto da REALIDA$D E$, dependendo da área de formação a que se destinam os alunos, no caso, do Ensino Superior. Então, a primeira etapa é a da OBSERVAÇÃO DA REALIDADE.

Os alunos são levados a observar a realidade em si, com seus próprios olhos e identificar-lhes as caracteristicas. Nesse momento, todas as perguntas possiveis podem e devem ser feitas, de modo a registrar os fenômenos que estão presentes nessa parcela da realidade social, tendo como foco principal o campo de estudos (Educação, Saúde, Direito etc.) mas podendose captar os diferentes aspectos que a ela estão relacionados (o econômico, o cultural, o ético, o administrativo, o social etc.).

Esta primeira etapa é o início de um processo de apropriação de informações pelos alunos. Se o professor desejar, poderá formular algumas questōes gerais que orientem as observações, para que estes não deixem de contemplar o que é específico da área de estudos.

As percepções primeiras, extraídas das aparências ou mesmo do senso comum começam a dar lugar a inquietações e explicações mais pensadas, mais informadas, ao mesmo tempo em que se percebem os aspectos positivos (equilíbrio, satisfação, organização etc.) e negativos (desequilíbrio, carências, dificuldades, desorganização etc.) dessa prática social observada.

Os problemas começam a surgir diante dos olhos curiosos e atentos dos observadores. Em geral são muitos, pois estamos num país de terceiro mundo, o que por si só justifica suficientemente este fato, em qualquer que seja a área de atuação localizada.

Com a perspectiva de, através dos estudos, poder contribuir para a transformação da realidade observada, um dos problemas é selecionado. Em geral se detecta uma necessidade ou uma ausência de algo que deveria estar presente ou acontecendo, dentro de padrões mínimos requeridos e então professor e alunos problematizam essa situação.

Problematizar, na nossa compreensão, significa formular o problema (uma questão, uma afirmação ou uma negação) a partir de fatos observados, por percebê-los como realmente problemáticos, inquietantes, instigantes ou inadequados. A problematização é relativa ao grupo, ao modo como o grupo olha a realidade, a partir dos conceitos e valores que possui, confrontados com o que observam, resultando num entendimento específico dessa situação, naquele momento.

Definido o problema a estudar, em que todo o grupo deverá estar de acordo, este será o objeto central de 
todos os trabalhos, de todo o processo. Embora os resultados sejam importantes, já que se pretende promover transformações, o processo todo também é altamente relevante, tendo em vista o desenvolvimento de atitudes científicas, políticas e éticas diante da realidade.

É preciso reforçar aqui que transformações ocorrem verdadeiramente. Se não na intensidade desejada junto ao contexto de onde se extraiu o problema, com certeza nas pessoas que vivem esse processo. A dinâmica de interações que se estabelece entre alunos e professor(es), entre esses e a realidade e com o conhecimento, é um processo construtivo irreversível. Mesmo orientando o processo, também o professor sofre transformações, pois a realidade é viva, atraente, multifacetada e em gera contraditória, o que a faz provocativa $e$ infinitamente potencializadora de novas indagações, reflexões e conhecimentos. Além disso, viver o processo com o grupo de alunos é sempre fator de aprendizagem e crescimento.

\subsection{2 - Pontos-chave}

A segunda etapa é a do estabelecimento de pontoschave. Se ao formular o problema se realizou uma espécie de sintese, nesta etapa volta-se para nova análise dos aspectos relacionados ao problema. Segundo BORDENAVE (1989, p.25), nesse momento "os alunos separam do que foi observado, o que é verdadeiramente importante do que é puramente superficial ou contingente". Com esse intuito, pode-se procurar identificar as possiveis causas e os determinantes sociais mais amplos do problema em estudo, contando-se para isso com os conhecimentos disponiveis no grupo assim como com outras informações que podem ser buscadas de imediato.

Os pontos-chave, então, podem ser expressos através de questões básicas que se apresentam para o estudo; através de afirmações (pressupostos) fundamentais sobre aspectos do problema; através de um conjunto de tópicos a serem investigados; através de princípios a serem considerados no estudo ou ainda outras formas, o que possibilita criatividade e flexibilidade ao tratamento do problema pelo grupo.

Pode-se perceber que a elaboração mental dos alunos avança, em relação à primeira etapa do estudo. Esta etapa da Problematização, diz Bordenave (1989, p.25), "constitui uma das razões mais importantes da superioridlade desta Pedagogia sobre as de Transmissão e Condicionamento".

\subsection{3 - Teorização}

Embora muitos aspectos teóricos (idéias, conceitos, representações) estejam presentes já nas duas etapas anteriores, a etapa da teorização é o momento de se construir respostas mais elaboradas para o problema. Os alunos buscam o por quê, o como, o onde, as incidências as relações etc., sobre o objeto de estudo. Os aspectos registrados como pontos-chave podem orientar essa busca de informações.

Costumamos explicar aos alunos que nesta fase, vamos buscar as informações onde quer que elas se encontrem. Podemos e devemos recorrer às teorias já existentes, disponiveis nos livros, revistas, relatos de pesquisas, artigos de jornais etc.. Podemos buscar informações também onde os fatos estão ocorrendo e sendo vividos pelas pessoas. Para isso podem ser formulados questionários, roteiros de entrevistas, fichas de observações, registros de acontecimentos, levantamento de informações em fichários, arquivos etc., assim como visitas a órgãos relacionados à administração ou desempenho profissional ligado ao estudo. Especialistas podem ser consultados. Usuários podem ser ouvidos.

A forma, a extensão e a profundidade da teorização dependem da conjugação de vários fatores como o tamanho do grupo de alunos e sua disponibilidade mental e emocional para o trabalho, o preparo do professor que o acompanha, o tempo disponivel, a criatividade, o interesse, a receptividade da comunidade ao estudo, os estudos já realizados sobre o problema, a organização do trabalho etc.

Os dados obtidos, registrados e tratados, são analisados e discutidos, buscando-se um sentido para eles, tendo sempre em vista o problema.

Bordenave chama a atenção para a importância do papel do professor nessa etapa, como estímulo constante para a participação ativa dos alunos, pois a tarefa de teorizar é sempre difícil e ainda mais quando não se possui o hábito de fazê-lo. Se a teorização é bem sucedida, afirma BORDENAVE (1989, p.25),

\section{"o aluno chega a 'entender' o problema, não somente em suas manifestações empíricas ou situacionais, assim como também os principios teóricos que o explicam. Essa etapa que compreende operações analiti- cas da inteligência é altamente enriquecedora e permite o crescimento mental dos alunos, (...) atingindo um poder de generalização e extrapolação considerá- vel".}

O autor aponta esses ganhos como uma razão a mais da superioridade da Pedagogia da Problematização sobre as de Transmissão e Condicionamento.

\subsection{4 - Hipóteses de solução}

Todo o estudo até aqui desenvolvido deve servir de base para a transformação da realidade. Então, que alternativas de solução podem ser apontadas para o problema estudado?

Esta é uma etapa em que a criatividade e a originalidade devem ser bastante estimuladas. Se os procedimentos comuns, se os padrões já conhecidos permitem a existência do problema, é preciso pensar e agir de modo inovador, para provocar a sua superação (ou solução).

Já sabemos que a teorização fornece os subsídios para essa etapa. No entanto, a teoria em si é ampla e fértil e não tem compromisso com a realidade. O professor deve ajudar os alunos a equacionar a questão da viabilidade e da factibilidade das suas hipóteses de solução confrontando-as com os dados da realidade (características especificas, condicionamentos, possibilidades, limitações). Bordenave aponta a situação de grupo como uma importante ajuda para essa confrontação 'ideal . 
real'. "Aqui vemos outra vantagem desta Pedagogia:.o aluno usa a realidade para aprender com ela, ao mesmo tempo em que se prepara para transformá-la" (BORDENAVE, 1989, p.25).

\subsection{5 - Aplicação à realidade}

Esta etapa é destinada à prática dos alunos na realidade social. É a fase que possibilita o intervir, o exercitar, o manejar situações associadas à solução do problema.

Dependendo da área do estudo, do grupo e do tempo disponivel, entre outros aspectos, essa prática poderá ser mais ou menos imediata, mais ou menos direta, mais ou menos intensa. O importante é garantir alguma forma de aplicação real do estudo no contexto a partir do qual teve origem o problema. A aplicação permite fixar as soluções geradas pelo grupo. Temos aprendido que no mínimo, os alunos podem e devem dar um retorno do estudo para os outros sujeitos envolvidos na realidade estudada, informando-os, ou seja: socializando o conhecimento produzido.

Ao elaborar as hipóteses de solução os alunos confrontaram suas idéias, suas propostas com os dados disponiveis, com as informações disponiveis até então. $\mathrm{Na}$ aplicação, o confronto é com o real acontecendo, em situação prática, dinâmica, interativa com os componentes do meio, onde o pensado se transforma em prática; onde se aprende a adequar a relação teoria-prática; onde a dialética da ação-reflexão é possibilitada e exercitada.

Dessa maneira, se completa o "arco" de Maguerez, cujos resultados podem estar sugerindo o reiniciar de muitos outros arcos.

\section{4 - HIPÓTESES DE SOLUÇÃO}

Vimos apresentando a Metodologia da Problematização como uma possível resposta ao problema identificado, desde o início da Teorização (item 3). Por suas características, por seus fundamentos, pela defesa que dela fazem os autores citados, reunimos um conjunto razoável de argumentos que colocam a Metodologia da Problematização como "uma alternativa metodológica que se apresenta com potencial pedagógico para preparar o aluno do Ensino Superior para atuar como profissional e como cidadão em seu meio".

Como afirmamos nos Pontos-Chave (item 2.1), para que o professor possa adotar uma metodologia de ensino é preciso conhecer suas características e experimentála, encontrando suas próprias razões de aplicá-la junto a seus alunos.

Nesse sentido, vimos experimentando a Metodologia da Problematização com diferentes grupos de alunos, na Universidade Estadual de Londrina, buscando identificar as condições necessárias de aplicação para produzir os efeitos (resultados) desejados, pois já sabemos que com diferentes organizações e condições, temos diferentes conseqüências, como citamos a seguir.

\section{1 - Algumas experiências e suas conseqüências}

4.1.1 - Em 1992, trabalhamos com uma turma de 23 alunos de Graduação em Ciências Biológicas, ao ministrar a Disciplina Didática.

Nesse caso, os alunos organizados em grupos, escolheram uma escola, Grau e série em que era oferecida a disciplina Ciências Biológicas, obtiveram o consentimento de um professor e passaram a observar algumas aulas. Identificaram um problema para estudo e desenvolveram os passos da Metodologia, até a elaboração do relatório final de todo o trabalho. Os resultados foram medianamente satisfatórios, pois a quebra da rotina das aulas desses alunos (em geral expositivas, com algumas atividades de laboratório) foi percebida por eles como algo estranho, trabalhoso, para alguns "confuso", apesar de todas as orientações e supervisões semanais aos grupos. A motivação da turma era baixa em relação à disciplina, já que a opção de todos era a de tornarem-se Biólogos e Pesquisadores e não professores de Biologia. A utilização da Metodologia pela primeira vez, com toda a certeza contribuiu para um grau menor de segurança, tanto por parte dos alunos quanto da professora.

4.1.2 - No $1^{\circ}$ Semestre de 1993, trabalhamos com uma turma de $2^{2}$ ano de Pedagogia (no $2^{2}$ semestre a metodologia foi diversificada, conforme objetivos e conteúdos da Disciplina Didática). Da mesma forma que os alunos de Ciências Biológicas, os alunos de Pedagogia escolheram o tipo de escola e série que gostariam de conhecer e observar. Enviamos ofício à Direção das Escolas, solicitando apoio e explicando o tipo de atividades que seriam desenvolvidas.

Das Escolas Municipais custamos a ter a aceitação. Vários contatos foram necessários junto à Secretaria Municipal de Educacão e com as Diretoras e por fim, já no $2^{\mathbf{2}}$ bimestre, os trabalhos foram iniciados. Vários grupos, com problemas diferentes sendo estudados ao mesmo tempo e pouco tempo, tanto dos alunos, quanto da professora para dar supervisão a todos.

A maior parte das barreiras foram vencidas e o trabalho realizado. As alunas perceberam e explicitaram a importância da experiência, principalmente pelo fato de terem tido contato com dados da realidade das escolas (administrativos, éticos, pedagógicos, políticos, etc.) antes de chegarem à fase dos estágios do curso, o que só ocorre no último ano. Além disso, valorizaram estudar problemas reais e não abstratos, em geral tratados como neutros e sem contexto.

Um dos grupos viveu situação interessante. No dia e hora marcados para a observação de aulas pelo grupo, em algumas turmas de alunos de mesma série, a Escola toda teve as atividades de sala interrompidas naquele período e foram apresentados dois filmes longos, um seguido do outro, sem nenhum tipo de tratamento pedagógico à situação.

Foi impossível problematizar algo de dentro da sala de aula, mas ficou evidente o problema da inadequada utilização dos recursos audiovisuais na escola, o que fol de pronto tomado para estudo pelo grupo.

As alunas desta turma deram retorno às Escolas que obsenaram, enviando uma cópia de seus trabalhos, após terem sido avaliados e aperfeiçoados em alguns aspectos de sua apresentação.

4.1.3 - Contrastando em vários aspectos com os dois primeiros registros, a experiência vivenciada como Assessora Pedagógica do Projeto Especial de Ensino na

- Outros dados sobre o PEEPIN podem ser conhecidos com a leitura da Ediçăo Especial do PEEPIN da Revista SEMINA, (jun./94) e outros documentos já divulgados sobre o Projeto.

Semina: Ci. Soc./Hum. v.16., n. 2, Ed. Especial, p. 9-19. out. 1995

16 
área da Saúde, o PEEPIN, revestiu-se de outras características.

O PEEPIN reune alunos de $1^{\circ}$ ano de todos os cinco cursos da área da saúde da UEL, num projeto em que se inscrevem como voluntários, para cumprir os $5 \%$ de carga horária destinada a Atividades Complementares de Ensino. Os grupos compostos com alunos (10 a 15) de todos os cursos, acompanhados por 1 ou 2 Instrutores (professores de diferentes disciplinas e cursos da UEL), trabalham durante um ano, às $4^{a} s$ feiras à tarde, com a Metodologia da Problematização, tendo como referência um Posto de Saúde do Município de Londrina.

Esta experiência, iniciada em março de 1992*, tem sido riquissima para a organização, análise e avaliação de muitos aspectos relativos à própria metodologia e à participação dos diferentes componentes do Projeto.

Aproximar-se desde cedo das questões de saúde da população, suas causas e conseqüências, acompanhados por docentes e supervisores dos serviços de saúde tem sido considerado de grande valor formativo pelos alunos, nos seus depoimentos, como mostram alguns exemplos, extraídos do Relatório anual do PEEPIN, ano 1993, apud BERBEL \& ITO (1994):

"É um projeto válido por ser inovador e
realmente nos coloca em contato com a
população (...)"
"(...) nos tira um pouco do ritmo das aulas
maçantes do ciclo básico".
"(..) reune e integra as profissões desde o
inicio do curso".
"Coloca o estudante mais próximo das pes-
soas com as quais futuramente trabalha-
rão".

Da parte dos Instrutores, vale a pena registrar alguns aspectos apontados em suas avaliações das atividades desenvolvidas em 1993:

\begin{abstract}
"A minha experiência acadêmica (ensino e extensão) e a vivência profissional têm mostrado que esse é o caminho para melhorar a qualidade da formação e da atuação profissional (...) Tenho certeza de que aprender observando e intervindo onde e quando os problemas acontecem é mais eficaz. Esse é o grande mérito da proposta". (Prof Vera)
\end{abstract}

"Aprendi tanto quanto os alunos. É gratificante obter resultados de interesse não só para os alunos e professor, mas para a comunidade. (...) Eu me envolvi bastante com o projeto pelo interesse nesta nova metodologia, com o objetivo de mudar as minhas aulas de Bioquímica no Básico". (Prof ${ }^{2}$ Célia)

"Embora nesse 20 ano do PEEPIN tenha participado apenas no $2^{\circ}$ semestre, creio que consegui acompanhar bem o GIM 13. Isso deve-se à minha evolução no emprego da metodologia da problematização, assim como ao meu entusiasmo crescente por esse projeto". (Prof Eloisa)
Em 1994, são 33 docentes envolvidos e cerca de 220 alunos, distribuídos em 14 grupos (em 14 pontos/postos da cidade, problematizando e estudando as questões de saúde da população.

4.1.4 - Na experiência 1 e 2 utilizamos a Metodologia da Problematização com nossos alunos da Graduação. $\mathrm{Na}$ experiência 3 , apoiamos professores de diversas disciplinas que acompanham os alunos da saúde no PEEPIN. Nas três oportunidades colhemos subsidios positivos para decidir aplicar essa metodologia também com alunos de Mestrado em Direito (2 turmas, uma em 1993-II e outra em 1994-II) e com alunos do Mestrado em Educação em 1994-I, a maioria deles professores da UEL.

Com os alunos de Direito, o trabalho, realizado como uma das atividades da Disciplina Metodologia do Ensino Superior, resultou muito interessante, pois como a experiência da maioria deles, professores ou não, era basicamente com a Pedagogia da Transmissão, esta alternativa Ihes ofereceu importantes reflexões em torno de possibilidades de atuação, conjugando conceitos de ensinar e aprender, formas de planejar e desenvolver o ensino, de avaliar etc., dentro de uma perspectiva mais crítica e construtiva, aprendida não apenas teoricamente, mas vivenciada, de maneira coerente aos princípios pedagógicos desenvolvidos na Disciplina.

4.1.5 - A experiência realizada junto aos alunos do Mestrado em Educação dispensa apresentação, pois os trabalhos serão relatados nos artigos que seguem nesta Revista, fato que nos alegra, pois comprova muito do que vimos escrevendo neste artigo, agora com a palavra dos próprios autores.

Cabe destacar, porém, que nos Cursos de Mestrado, os estudos foram feitos individualmente ou no máximo em duplas de alunos. Quando feito em duplas, as próprias duplas manifestaram a riqueza que foram as discussões para a elaboração do trabalho. Os alunos, profissionais de tempo integral e sem bolsa e licença para realizar o Mestrado, ressentem-se de falta de tempo para o trabalho coletivo, ao que acrescentariamos também a lastimável falta de hábito, conseqüência do tipo de relações sociais que vivemos há muito em nosso pais.

O aspecto positivo do trabalho de cada um foi o de poder localizar na sua realidade concreta de atuação uma necessidade ou dificuldade e então problematizála, o que permitiu uma nova postura pessoal diante de sua própria prática, compartilhada com os colegas em certos momentos da Disciplina e ao final do trabalho, além de envolver outras pessoas em seus estudos (professores e alunos, dependendo do problema).

Também para nós, enquanto coordenamos as atividades, ocorre a dificuldade de tempo para supervisionar a todos os diferentes trabalhos (tendo que conciliar com as possibilidades de horário dos alunos), o que às vezes traz prejuizos para o processo.

Dessa maneira, refletindo sobre as dificuldades e alegrando-nos com os resultados possiveis a cada situação, vamos construindo o nosso referencial teórico. metodológico para utilizaçāo da Metodologia da Problematizaçāo.

\section{2 - Mais algumas hipóteses, com vistas à soluçāo do problema}

Completando este item do texto, podemos acrescen- 
tar as seguintes hipóteses de solução para que essa Metodologia, ao ser desenvolvida com alunos do Ensino Superior, realmente atinja os resultados esperados.

4.2.1 - Os professores que se disponham a trabalham com a Metodologia da Problematização devem aprofundar estudos no sentido de sua fundamentação teórica, já que esta é uma metodologia que tem uma proposta políticopedagógica bastante clara. Nesse sentido, não pode ser tomada como uma técnica qualquer, avulsa, neutra, mas que tem raizes históricas, princípios fundamentais e que só podem repercutir positivamente, se utilizada de forma compatível com uma postura docente crítica, reflexiva e politicamente compromissada com os destinos da Educação de toda a População. Essa é, de nossa parte, mais que uma hipótese, uma certeza, mas que requer também da nossa parte, a continuidade dessa elaboração.

4.2.2 - Transformar a realidade, transformar a educação não é um trabalho para pessoas isoladas. Portanto a nossa afirmação é pelo trabalho coletivo sempre, de grupos de alunos com um ou mais professores. Este aspecto porém, demanda ações administrativas, de organização do trabalho, que acaba incidindo sobre os custos para as Instituições. Diante disso, há que se buscar elaborar projetos bem fundamentados, para conquistar os espaços, as adesões e apoios necessários como vem acontecendo com o Projeto PEEPIN. É preciso aliar capacidade técnica, vontade política e algum esforço adicional de um grupo de pessoas com o mesmo objetivo e compromisso social.

4.2.3 - Para que as experiências pedagógicas possam ser validadas, necessitam de um acompanhamento e avaliação sistemáticos. $O$ registro detalhado do processo desenvolvido e das reflexões feitas por professores e alunos em cada situação, possibilitam tanto o aperfeiçoamento do processo, quando usado para o alcance dos objetivos, quanto o aperfeiçoamento deste para novas experiências, o que sem dúvida é um ingrediente decisivo para a construção teórico-metodológica necessária para o grau de Ensino Superior, ainda bastante precária, e para a qual acreditamos que a Metodologia da Problematização possa contribuir.

4.2.4 - Para que a Metodologia da Problematização possa preparar o aluno do Ensino Superior para atuar como profissional e cidadão em seu meio, não basta que seja utilizada uma só vez, por um só professor, em sua disciplina. É preciso então sensibilizar mais professores para conhecer e aplicar, de preferência através de projetos mais abrangentes e duradouros, garantindo-se 0 tempo e as condições necessários para a sedimentação dos conhecimentos e das atitudes desenvolvidas. Nesse ponto, esta hipótese confunde-se um pouco com um sonho, mas que acreditamos valer a pena ser expressado e compartilhado, com vistas à sua realização.

\section{5 - APLICAÇÃo À REALIDADE}

Esta etapa, na Metodologia da Problematização, é a etapa da prática, da realização das hipóteses de solução mais viáveis e factíveis. É a etapa da intervenção, visando uma ação social transformadora.

No caso deste texto, ele já contêm nas páginas anteriores muito do prático que realizamos, restando-nos completá-lo, com algumas idéias conclusivas, até este momento.
Lemos de ANTONIO GRAMSCI (Apud SILVA JUNIOR, 1994, p.98) a sua afirmação de que:

"O fato de que uma multidão de homens seja conduzida a pensar coerentemente e de maneira unitária a realidade presente é um fato 'filosófico' bem mais importante e 'original' do que a descoberta, por parte de um 'gênio filosófico', de uma nova verdade que permaneça como patrimônio de pequenos grupos de intelectuais".

GRAMSCI nos inspira a pensar que a divulgação de idéias é uma ação decisiva para submetê-las à discussão, à crítica, à apreciação, aceitação ou aperfeiçoamento. A nossa pretensão não é a de "conduzir multidões...", como indicou Gramsci, mas a de socializar idéias, mesmo durante o processo de sua elaboração, buscando parceria entre professores do Ensino Superior para aplicálas, reconstrui-las e disseminá-las.

5.1 - Isso o fazemos através da publicação deste texto, na Revista da Universidade, apresentando aos seus leitores a Metodologia da Problematização e ao mesmo tempo introduzindo um conjunto de artigos gerados dentro dessa direção. A própria elaboração do texto seguindo os passos da Metodologia analisada é um exercicio de aplicação prática de sua linha metodológica.

5.2 - Uma outra possibilidade de aplicação que estamos encaminhando é a proposta de elaboração de um projeto de ensino com a Metodologia da Problematização, para ser desenvolvido com a $1^{\mathrm{a}}$ turma do curso de Pedagogia noturno, que inicia o curso em 1995. Acreditamos que seja uma forma de retirar os alunos da aula tradicional e levá-los, logo no inicio do curso para conhecer a realidade do ensino de algumas escolas, focalizando a sala de aula, o ensino, a educação escolar noturna, enquanto ela ocorre, para que possam contar com essas informações em seus estudos pedagógicos no curso como um todo.

5.3 - Uma terceira aplicação deste estudo é a clareza que atingimos quanto à necessidade de proceder a avaliação ampla do uso da metodologia, controlando suas condições versus seus efeitos reais na prática social de seus participantes. Estamos programando esta atividade para 1995, junto aos participantes do PEEPIN e buscando, já em 1994, ouvir a todos os alunos de Mestrado em Direito e Educação, quanto ao significado que tem tido para eles experimentar a Metodologia da Problematização, tal como a propomos.

5.4 - Outra aplicação do estudo é o uso deste texto como um instrumento de comunicação escrita nas oportunidades que temos e teremos de dar assessoria a professores do Ensino superior, assim como em encontros com professores de outros graus de ensino.

5.5 - A disseminação das idéias deste texto tambèm será feita em eventos nacionais que tratam do ensino e especialmente do Ensino Superior.

5.6 - Por último, a proposta que nos fazemos de prosseguir nos estudos, tendo já encaminhado à Biblioteca Central da UEL um pedido de amplo levantamento de referências sobre este Método e o tratamento do tema no pais e fora dele, de modo a comparar experiências e explicações com as de outros autores, alèm da justificativa epistemológica para essa forma de orientar a aquisi- 
ção e a construção do conhecimento.

Concluímos este texto com um depoimento de Maria Aparecida, como um exemplo das respostas que temos obtido de nossos alunos de Mestrado que experimentaram pela primeira vez a Metodologia da Problematização.

"Para mim, vivenciar a metodologia da problematização significou ter momentos de questionamentos, oportunidades de critica, liberdade para aprender e ensinar em busca de soluções. Criamos meios para viabilizar uma ação concreta - a intervenção na realidade. Tivemos oportunidade de não separar o pensar e o agir, pois unimos a teoria com a prática real e elaboramos uma interpretação no sentido da transformação de uma situação vigente. A metodologia da problematização é uma situação pedagógica que estimula a participação, a criatividade e a criticidade do aluno, sendo o professor um agente integrante e participante no sentido de estar acompanhando e orientando o aluno. (...) A metodologia da problematização, introduzida no ensino superior juntamente com outras situações pedagógicas estimuladoras, proporcionarão um crescimento do aluno e professor, onde a felicidade possivelmente permeará as relaçōes e as atividades desenvolvidas". (Prof ${ }^{2}$ Maria Aparecida, aluna do Mestrado em Educação da UEL, 1994)

BERBEL, N.A.N. Methodology of Problematization: a methodological alternative suitable for Higher Education. Semina: Ci. Soc./Hum., Londrina, v16. n. 2., Ed. Especial, p.9-19, out. 1995.

ABSTRACT - Due to the reaffirmed evidence that the Pedagogy of Knowledge Transmission in Higher Education is predominant which is characterized as a teacher centered method and his knowledge, instead of on the student learning process, in this article a Methodology of Problematization is presented as an alternative with great potential to prepare the new professional and citizen that is required for a rapid changing society. This article was written following the steps of the same methodology: observation of the reality and definition of a problem to be studied, key points, theorization, hypothesis for the solutions, and its aplication on the reality. The characteristics of this methodology are explained, discussed, analysed, based on Juan Dias Bordenave and other authors. In addition, some experiences are stressed as support for the process of action-reflexion, for the solution hypothesis and its possible applications to the reality closer to Higher Education context from wich the problem was formulated.

\section{KEY WORDS - Problematization methodology; Teaching methods; Higher Education}

\section{REFERÊNCIAS BIBLIOGRÁFICAS}

BERBEL, Neusi Aparecida Navas, Currículo médico e compromisso social. Divulgaçáo om Saúde para Debate, Londrina, n.9, p.54-59, ago. 1994, Publicação editada pelo Centro Brasileiro de Estudos de Saúde - CEBES

BERBEL, Neusi Aparecida Navas. Metodologia do Ensino Superior: análise das características e do significado da sua existêncla na formação do professor de 3* Grau. São Paulo, 1992. Tese (Doutorado) - Faculdade de Educação da Universidade de São Paulo, 1992.

BERBEL, Neusi Aparecida Navas; ITO, Ana Misako Yendo. PEEPIN Projeto multiprofissional e interdlisciplinar de ensino na área da saúde - relato da experiência em desenvolvimento. Universidade Estadual de Londrina, [1994], 13p. (mimeo.)

BORDENAVE, Juan Diaz. Alguns fatores pedagógicos. In: MINISTÉRIO DA SAÚDE, Secretaria Geral. Secretaria de Modernização Administrativa e Recursos Humanos. Brasilia, 1989, p.19-26: Capacitação pedagógica para instrutores/supervisores da área da saúde.

BORDENAVE, Juan Díaz; PEREIRA, Adair Martins. Estratégias de ensino aprendizagem. 4.ed. Petrópolis: Vozes, 1982

FONSECA, Dirce Mendes da. Gestão e educação. Universidade e Socledade, São Paulo: Andes, n.7, p.45-49, jun.1994.

LIBÂNEO, José Carlos. Democratização da escola pública. A pedagogia crítico-social dos conteúdos. São Paulo: Loyola, 1985.

MACHADO, Carmen Esther Grumadas. Caracteristicas do bom profeseor e do bom aluno do Curso de Medicina Veterinária da
Universidade Estadual de Londrina, na opinião dos sujeitos envolvidos. Londrina, 1994, 84 fls. Monografia (Especialização em Metodologia do Ensino Superior) Departamento de Educação, Universidade Estadual de Londrina.

MOREIRA, Ana Marcia Andrade. Fatores mobilizadores do sucesso escolar de adultos universitários do ponto de vista de professores e alunos do Curso de Medicina na Universidade Estadual de Londrina-Pr. Londrina, 1994, 142 fls. Monografia (Especialização em Metodologia do Ensino superior) Departamento de Educação, Universidade Estadual de Londrina.

NÉRICl, Imídeo Giusepe. Educação e Metodologia. Rio de Janeiro: Fundo de Cultura, 1973.

NOGUEIRA, Roberto Passos. Perspectivas da qualidade em saúde. Rio de Janeiro: Qualitymark, 1994.

SAVIANI, Dermeval. Escola e Democracia. São Paulo: Cortez, 1984.

SILVA JUNIOR, Celestino Alves. Pós-Graduação em educação e socialização do conhecimento. Universidade e Sociedade, São Paulo: Andes, n. 7, p.98-101, jun. 1994.

SOUZA, Alina Maria de Almeida et al. Processo educativo nos serviços de saúde. Brasília: Organização Pan-Americana da Saúde, 1991. (Série Desenvolvimento de Recursos Humanos, $n^{2} 1$ ).

VÁSQUEZ, Adolfo Sánchez. Filosofia da Praxis. 4.ed. Rio de Janeiro: Paz e Terra, 1977. 